\title{
Optimal Hydration Biomarkers: Consideration of Daily Activities
}

\author{
Colleen X. Muñoz Amy L. McKenzie Lawrence E. Armstrong \\ Human Performance Laboratory, Department of Kinesiology, University of Connecticut, \\ Storrs, CT, USA
}

\author{
Key Words \\ Hydration indices · Dehydration · Osmolality
}

\section{Introduction}

Water intake and hydration status have recently gained attention as one of the many, and potentially manipulable, factors associated with disease development and wellbeing [1-7]. Researchers have explored a variety of physiological dysfunctions implicated with chronic low water intake and hypohydration, but particular interest resides in the study of obesity and related disease states due to overwhelming prevalence. However, the current lack of a hydration assessment gold standard greatly impedes our attempts to link water intake and negative health outcomes as well as to make public dietary guidelines.

Current hydration biomarkers include blood, saliva, and urine sampling subjected to a variety of quantification methods (osmolality, specific gravity, volume, etc.). Recent work from our laboratory [8] contributed to the ongoing quest to identify optimal selection of hydration biomarkers, but through consideration of the context under which body water loss occurs. We present two scenarios when selecting optimal hydration biomarkers: i) active versus passive body water loss, and ii) single versus serial measurements.

\section{Methodology}

We examined 23 healthy, recreationally active males (age $=22 \pm 3$ years; mass $=77.3 \pm$ $12.8 \mathrm{~kg}$; height $=179.9 \pm 8.8 \mathrm{~cm}$; body fat $=10.6 \pm 4.5 \%$ ). Participants completed one familiarization trial, recorded their complete dietary intake for 3 consecutive days, and underwent 
two experimental trials. Individual water intake was prescribed for the day prior to experimental trials as an average intake from their 3-day dietary records. Furthermore, participants replicated all food consumption the day prior to experimental trials.

Two experimental trials were conducted in a hot environment (about $36^{\circ} \mathrm{C}$, approximately 50\% relative humidity) to examine: i) passive dehydration (PAS), where participants simply sat in the hot environment for $5 \mathrm{~h}$, and ii) active dehydration (ACT), where participants cycled in the hot environment at a moderate intensity (about $68 \%$ of age-predicted maximal heart rate) for $5 \mathrm{~h}$. Participants did not consume foods or water during these trials. Upon each percent body mass loss, participants provided blood, saliva, and urine samples. Researchers measured blood serum osmolality $\left(\mathrm{S}_{\text {osm }}\right)$, salivary osmolality $\left(\mathrm{V}_{\text {osm }}\right)$, urine osmolality $\left(\mathrm{U}_{\mathrm{osm}}\right)$, volume $\left(\mathrm{U}_{\mathrm{vol}}\right)$, and specific gravity $\left(\mathrm{U}_{\mathrm{sg}}\right)$.

\section{Passive versus Active Dehydration}

We uncovered that the context under which body water losses occur does influence the ability of hydration biomarkers to assess dehydration. Largely, we found during PAS that progressive and large changes were observed more so in urinary compared to serum and salivary variables. Conversely, we found during ACT that serum and salivary markers responded more precisely to body water losses than did urinary variables (fig. 1). These findings are likely explained through autonomic regulation and hemoconcentration during heat and exercise exposure [9], which concentrates the extracellular compartment, primary saliva [10], and diverts cardiac output away from the kidneys [11-13]. In support of these findings, we were able to compare mean differences between PAS and ACT trials at $1 \%$ body mass loss, and found that even mild dehydration elicited statistically and physiologically meaningful differences between the two methods of body water loss (table 1). In essence, these findings indicate that exercise exaggerated changes in $S_{\text {osm }}$ and $V_{o s m}$, and that urinary markers best represented water losses during PAS.

\section{Single versus Serial Measurement}

Statistical tools for measuring diagnostic accuracy and reference change values (RCV) permitted evaluation of hydration biomarker utility with availability of single versus serial measurements, respectively.

\section{Diagnostic Accuracy}

In order to evaluate hydration biomarker utility with a single measurement, we operationally defined a dehydrated state as $2 \%$ body mass loss, as this degree of body water loss typically provokes physiological and psychological dysfunction [5, 14-17]. Diagnostic accuracy statistics included: i) receiver operating characteristic (ROC) to define criterion values for each diagnostic test, ii) area under the ROC curve (AUC) to summarize diagnostic accuracy, and iii) sensitivity, specificity, and positive likelihood ratio (+LR) to assist in clinical decision making. The best combination of sensitivity (the probability of a true positive) and specificity (the probability of a true negative) allows the practitioner to use the ROC-derived criterion value with confidence to diagnose dehydration with the respective hydration biomarker. Great practicality exists in the $+\mathrm{LR}$, as high ratios indicate that true positives are much more likely than false positives.

Diagnostic accuracy was conducted for ACT only, as PAS resulted in an insufficient sample size greater than $2 \%$ body mass loss. We found that $\mathrm{V}_{\text {osm }}$ and $\mathrm{S}_{\text {osm }}$ most accurately assessed 
Fig. 1. Hydration biomarker change $(\Delta$ means $\pm \mathrm{SE})$ with body mass loss via PAS (left) and ACT (right): a serum osmolality, b salivary osmolality, c urine osmolality, d urine volume, and e urine specific gravity. Significant differences $(\mathrm{p}<0.05)$ indicated with * compared to $0 \%$ mass change, † compared to $-1 \%$ mass change, ₹ compared to $-2 \%$ mass change, and $\S$ compared to $-3 \%$ mass change.

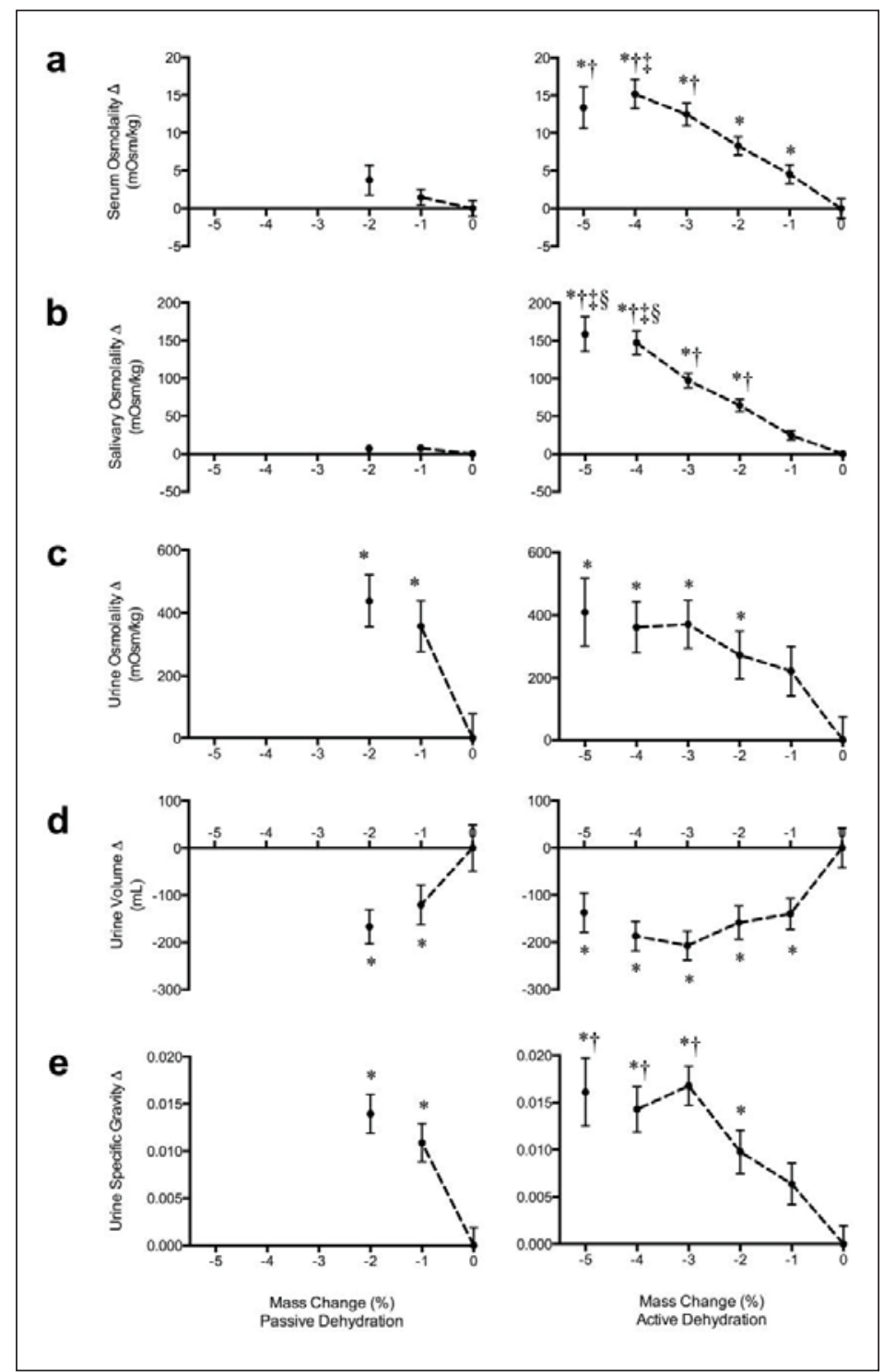

Table 1. Hydration indices at $0 \%$ (pre-trial) and $-1 \%$ body mass change during PAS and ACT

\begin{tabular}{|c|c|c|c|c|c|c|}
\hline \multirow[t]{2}{*}{ Hydration biomarker } & \multicolumn{2}{|c|}{$0 \%$ mass change } & \multicolumn{2}{|c|}{$-1 \%$ mass change } & \multirow[t]{2}{*}{$\mathrm{n}$} & \multirow[t]{2}{*}{$\mathrm{p}$} \\
\hline & PAS & ACT & PAS & ACT & & \\
\hline Serum osmolality, mOsm $\cdot \mathrm{kg}^{-1}$ & $295 \pm 4$ & $296 \pm 4$ & $296 \pm 4$ & $301 \pm 4$ & 22 & $<0.01^{\mathrm{a}}$ \\
\hline Salivary osmolality, $\mathrm{mOsm} \cdot \mathrm{kg}^{-1}$ & $68 \pm 14$ & $64 \pm 9$ & $74 \pm 14$ & $90 \pm 24$ & 21 & $<0.01^{\mathrm{a}}$ \\
\hline Urine osmolality, $\mathrm{mOsm} \cdot \mathrm{kg}^{-1}$ & $466 \pm 267$ & $439 \pm 252$ & $895 \pm 207$ & $661 \pm 192$ & 11 & $0.01^{\mathrm{a}}$ \\
\hline Urine volume, ml & $266.8 \pm 165.4$ & $231.0 \pm 130.1$ & $106.4 \pm 79.4$ & $91.2 \pm 46.4$ & 11 & 0.59 \\
\hline Urine specific gravity & $1.011 \pm 0.006$ & $1.012 \pm 0.006$ & $1.023 \pm 0.006$ & $1.018 \pm 0.006$ & 11 & 0.06 \\
\hline
\end{tabular}

${ }^{a}$ Indicates differences between PAS and ACT at $-1 \%$ body mass change $(\mathrm{p}<0.05)$.

PAS $=$ Passive dehydration $;$ ACT $=$ active dehydration .

Variation in sample size (n) at $-1 \%$ body mass change attributable to number of paired samples (sample provided by subject for both PAS and ACT) 
Table 2. Receiver operating characteristic curve analysis of hydration biomarkers during active dehydration when only a single measurement is available

\begin{tabular}{llllll}
\hline Hydration biomarker & AUC & $\begin{array}{l}\text { Estimate } \\
\text { SE }\end{array}$ & $\begin{array}{l}\text { Criterion } \\
\text { value }\end{array}$ & $\begin{array}{l}\text { Sensitivity, } \\
\%\end{array}$ & $\begin{array}{l}\text { Specificity, } \\
\%\end{array}$ \\
\hline Serum osmolality, mOsm $\cdot \mathrm{kg}^{-1}$ & $0.91^{\mathrm{a}}$ & 0.03 & 303 & 83 & 83 \\
Salivary osmolality, $\mathrm{mOsm} \cdot \mathrm{kg}^{-1}$ & $0.94^{\mathrm{a}}$ & 0.03 & 108 & 86 & 91 \\
Urine osmolality, mOsm $\cdot \mathrm{kg}^{-1}$ & $0.80^{\mathrm{a}, \mathrm{b}}$ & 0.05 & 631 & 80 & 65 \\
Urine volume, ml & $0.87^{\mathrm{a}}$ & 0.04 & 90 & 79 & 79 \\
Urine specific gravity & $0.89^{\mathrm{a}}$ & 0.04 & 1.020 & 81 & 81 \\
\hline
\end{tabular}

${ }^{a}$ Denotes that AUC was significantly different from change.

${ }^{b}$ Denotes that AUC was significantly different from salivary osmolality $(\mathrm{p}<0.05)$; a trend was observed between serum and urine osmolality $(p=0.06)$.

AUC $=$ Area under curve; $\mathrm{SE}=$ standard error .

Table 3. Positive likelihood ratios (+LR) and corresponding values for hydration biomarkers during active dehydration when only a single measurement is available

\begin{tabular}{lll}
\hline Hydration biomarker & $+\mathrm{LR}$ & Measured value \\
\hline Serum osmolality & 11.73 & $306 \mathrm{mOsm} \cdot \mathrm{kg}^{-1}$ \\
& 4.88 & $303 \mathrm{mOsm} \cdot \mathrm{kg}^{-1}$ \\
Salivary osmolality & 1.82 & $298 \mathrm{mOsm} \cdot \mathrm{kg}^{-1}$ \\
& 10.02 & $116 \mathrm{mOsm} \cdot \mathrm{kg}^{-1}$ \\
Urine osmolality & 9.65 & $108 \mathrm{mOsm} \cdot \mathrm{kg}^{-1}$ \\
& 1.92 & $73 \mathrm{mOsm} \cdot \mathrm{kg}^{-1}$ \\
Urine volume & 8.38 & $1,146 \mathrm{mOsm} \cdot \mathrm{kg}^{-1}$ \\
& 2.29 & $631 \mathrm{mOsm} \cdot \mathrm{kg}^{-1}$ \\
Urine specific gravity & 1.97 & $582 \mathrm{mOsm} \cdot \mathrm{kg}^{-1}$ \\
& 10.53 & $31 \mathrm{ml}$ \\
& 3.70 & $90 \mathrm{ml}$ \\
& 1.99 & $143.2 \mathrm{ml}$ \\
& 10.50 & 1.024 \\
& 4.22 & 1.020 \\
\hline
\end{tabular}

dehydration (table 2), which supports our observation that these variables responded more drastically to body water loss than urinary variables during ACT. The +LR for $\mathrm{S}_{\text {osm }}$ (table 3 ) tells the practitioner that, e.g., a value of $303 \mathrm{mOsm} \cdot \mathrm{kg}^{-1}$ occurs 4.88 times more often in a dehydrated than sufficiently hydrated individual who has been exercising.

\section{Reference Change Values}

RCV statistics evaluate the utility of a test with serial measurement. This requires preliminary measures of analytical and biological variation, which includes coefficients of variation for the analytical device $\left(\mathrm{CV}_{\mathrm{A}}\right)$, and interindividual $\left(\mathrm{CV}_{\mathrm{I}}\right)$ and intraindividual $\left(\mathrm{CV}_{\mathrm{G}}\right)$ variation. The derived RCV (table 4) in this investigation indicates a meaningful change (expressed as a percentage or unit) in the hydration biomarker indicative of a dehydrated state. Subsequent analyses included the index of individuality (II) which indicates usefulness for populationbased reference intervals, where a value greater than 1.4 signifies high usefulness and less than 0.6 suggests low usefulness. The index of heterogeneity (IH) assists in validating the $\mathrm{RCV}$, which, in our investigation, was an IH greater than 2 . 
Table 4. Analytical and biological coefficients of variation and indices of variability for hydration biomarkers when serial measurements are available

\begin{tabular}{lllllllll}
\hline Hydration biomarker & $\mathrm{CV}_{\mathrm{A}}^{\mathrm{a}}$ & $\mathrm{CV}_{\mathrm{I}}^{\mathrm{b}}$ & $\mathrm{CV}_{\mathrm{G}}{ }^{\mathrm{c}}$ & $\mathrm{II}^{\mathrm{d}}$ & $\mathrm{IH}^{\mathrm{e}}$ & $\mathrm{RCV},{ }^{\mathrm{f}}$ & $\mathrm{RCV}$, unit $^{\mathrm{f}}$ & Decision level \\
\hline Serum osmolality, mOsm $\cdot \mathrm{kg}^{-1}$ & 0.3 & 0.9 & 0.9 & 0.96 & 0.96 & 2.12 & 6 & $302 \pm 4$ \\
Salivary osmolality, m0sm $\cdot \mathrm{kg}^{-1}$ & 2.5 & 10.1 & 18.4 & 0.56 & 7.34 & 24.21 & 16 & $84 \pm 16$ \\
Urine osmolality, mOsm $\cdot \mathrm{kg}^{-1}$ & 0.4 & 23.9 & 48.2 & 0.49 & 16.87 & 55.67 & 255 & $708 \pm 257$ \\
Urine volume, ml & negligible & 41.1 & 15.0 & 2.74 & 29.08 & -95.96 & -242 & $9 \pm 150$ \\
Urine specific gravity & negligible & 0.3 & 0.3 & 0.79 & 0.20 & 0.65 & 0.007 & $1.018 \pm 0.006$ \\
Body mass, \% loss & negligible & 0.5 & 10.9 & 0.05 & 0.36 & -1.20 & -1.20 & $-1.2 \pm 0.2$ \\
\hline
\end{tabular}

${ }^{\mathrm{a}} \mathrm{CV}_{\mathrm{A}}=$ Coefficient of variation for the analytical device. When possible, $\mathrm{CV}_{\mathrm{A}}$ was measured with standard solutions specific to the measurement range; otherwise, actual samples were used. All values are expressed as a percentage.

${ }^{\mathrm{b}} \mathrm{CV}_{\mathrm{I}}=$ Intraindividual coefficient of variation.

${ }^{c} \mathrm{CV}_{\mathrm{G}}=$ Interindividual coefficient of variation. $\mathrm{CV}_{\mathrm{I}}$ and $\mathrm{CV}_{\mathrm{G}}$ measured with all pre-trial samples from passive dehydration and active dehydration trials and expressed as percentages.

${ }^{\mathrm{d}} \mathrm{II}=$ Index of individuality.

e $\mathrm{IH}=$ Index of heterogeneity.

${ }^{f} \mathrm{RCV}=$ Reference change value expressed as a percentage, or specific to the unit of measurement.

Due to the nature of RCV statistics, the values reported are irrespective of the method through which body water loss occurred (active vs. passive). We found that only three hydration biomarkers demonstrated valid RCV ( $\mathrm{IH}>2$ ): $\mathrm{S}_{\mathrm{osm}}, \mathrm{U}_{\mathrm{sg}}$, and body mass loss. For example, a change in serial $U_{\mathrm{sg}}$ measurement of 0.007 would indicate a dehydrated state according to our findings (table 4). Furthermore, only $\mathrm{U}_{\mathrm{vol}}$ had a high enough II considered useful for population-based reference intervals, while it did not result in a valid RCV. This implies good utility for interpretation of hydration state among healthy populations based on typical variation, but not for serial measurement with acute dehydration, respectively.

\section{Conclusion}

This investigation elucidated the need to consider previous or concurrent activities, and the frequency of sample measurement when selecting hydration biomarkers. Largely, we found that $\mathrm{S}_{\text {osm }}$ and $\mathrm{V}_{\mathrm{osm}}$ during ACT in the heat, and urinary markers during PAS in the heat, were the most suitable biomarkers given the context or means of dehydration. When only single measurements are available during ACT, $\mathrm{S}_{\text {osm }}$ and $\mathrm{V}_{\text {osm }}$ established the greatest efficacy. Regardless of the method of body water loss, $\mathrm{S}_{\mathrm{osm}}, \mathrm{U}_{\mathrm{sg}}$, and body mass loss resulted as the most valuable serial measurement dehydration indices. In essence, the context surrounding body water loss should dictate selection of hydration biomarkers to appropriately identify hydration status before research examining the influence of chronic water intake on health outcomes progresses.

\section{Disclosure Statement}

The authors declared no conflict of interest. 
Muñoz et al.: Optimal Hydration Biomarkers: Consideration of Daily Activities

\section{References}

1 Armstrong LE: Challenges of linking chronic dehydration and fluid consumption to health outcomes. Nutr Rev 2012;70(suppl 2):S121-127.

-2 Keller U, Szinnai G, Bilz S, Berneis K: Effects of changes in hydration on protein, glucose and lipid metabolism in man: impact on health. Eur J Clin Nutr 2003;57(suppl 2):S69-74.

-3 Altieri A, La Vecchia C, Negri E: Fluid intake and risk of bladder and other cancers. Eur J Clin Nutr 2003; 57(suppl 2):S59-68.

4 Maughan RJ: Impact of mild dehydration on wellness and on exercise performance. Eur J Clin Nutr 2003; 57 (suppl 2):S19-23.

5 Armstrong LE, Ganio MS, Casa DJ, Lee EC, McDermott BP, Klau JF, Jimenez L, Le Bellego L, Chevillotte E, Lieberman HR: Mild dehydration affects mood in healthy young women. J Nutr 2012;142:382-388.

6 Schliess F, Richter L, vom Dahl S, Haussinger D: Cell hydration and mTOR-dependent signalling. Acta Physiol (Oxf) 2006;187:223-229.

-7 Tang C, Zelenak C, Volkl J, Eichenmuller M, Regel I, Frohlich H, Kempe D, Jimenez L, Le Bellego L, Vergne S, Lang F: Hydration-sensitive gene expression in brain. Cell Physiol Biochem 2011;27:757-768.

-8 Munoz CX, Johnson EC, Demartini JK, Huggins RA, McKenzie AL, Casa DJ, Maresh CM, Armstrong LE: Assessment of hydration biomarkers including salivary osmolality during passive and active dehydration. Eur J Clin Nutr 2013;67:1257-1263.

-9 Harrison MH: Heat and exercise. Effects on blood volume. Sports Med 1986;3:214-223.

10 Proctor GB, Carpenter GH: Regulation of salivary gland function by autonomic nerves. Auton Neurosci 2007; 133:3-18.

11 Rowell LB, Marx HJ, Bruce RA, Conn RD, Kusumi F: Reductions in cardiac output, central blood volume, and stroke volume with thermal stress in normal men during exercise. J Clin Invest 1966;45:1801-1816.

12 Radigan LR, Robinson S: Effects of environmental heat stress and exercise on renal blood flow and filtration rate. J Appl Physiol 1949;2:185-191.

13 Poortmans JR: Exercise and renal function. Sports Med 1984;1:125-153.

14 Armstrong LE, Casa DJ, Millard-Stafford M, Moran DS, Pyne SW, Roberts WO: American College of Sports Medicine position stand. Exertional heat illness during training and competition. Med Sci Sports Exerc 2007; 39:556-572.

15 Sawka MN, Burke LM, Eichner ER, Maughan RJ, Montain SJ, Stachenfeld NS: American College of Sports Medicine position stand. Exercise and fluid replacement. Med Sci Sports Exerc 2007;39:377-390.

16 Cheuvront SN, Ely BR, Kenefick RW, Sawka MN: Biological variation and diagnostic accuracy of dehydration assessment markers. Am J Clin Nutr 2010;92:565-573.

17 Ganio MS, Armstrong LE, Casa DJ, McDermott BP, Lee EC, Yamamoto LM, Marzano S, Lopez RM, Jimenez L, Le Bellego L, Chevillotte E, Lieberman HR: Mild dehydration impairs cognitive performance and mood of men. $\mathrm{Br}$ J Nutr 2011;106:1535-1543. 